\title{
Multidisciplinary Perspectives on Human Capital and Information Technology Professionals
}

Vandana Ahuja

Jaypee Institute of Information Technology, India

Shubhangini Rathore

IBS Gurgaon, India 
Published in the United States of America by

IGI Global

Information Science Reference (an imprint of IGI Global)

701 E. Chocolate Avenue

Hershey PA, USA 17033

Tel: 717-533-8845

Fax: 717-533-8661

E-mail: cust@igi-global.com

Web site: http://www.igi-global.com

Copyright ( $\odot 2018$ by IGI Global. All rights reserved. No part of this publication may be reproduced, stored or distributed in any form or by any means, electronic or mechanical, including photocopying, without written permission from the publisher. Product or company names used in this set are for identification purposes only. Inclusion of the names of the products or companies does not indicate a claim of ownership by IGI Global of the trademark or registered trademark.

Library of Congress Cataloging-in-Publication Data

Names: Ahuja, Vandana, editor. I Rathore, Shubhangini, 1986- editor.

Title: Multidisciplinary perspectives on human capital and information

technology professionals / Vandana Ahuja and Shubhangini Rathore, editors.

Description: Hershey : Information Science Reference, [2018]

Identifiers: LCCN 2017038370| ISBN 9781522552970 (hardcover) I ISBN

9781522552987 (ebook)

Subjects: LCSH: Personnel management. I Information technology--Management.

Classification: LCC HF5549 .M837 2018 I DDC 004.068--dc23 LC record available at https://lccn.loc.gov/2017038370

This book is published in the IGI Global book series Advances in Information Security, Privacy, and Ethics (AISPE) (ISSN: 1948-9730; eISSN: 1948-9749)

British Cataloguing in Publication Data

A Cataloguing in Publication record for this book is available from the British Library.

All work contributed to this book is new, previously-unpublished material. The views expressed in this book are those of the authors, but not necessarily of the publisher.

For electronic access to this publication, please contact: eresources@igi-global.com. 


\title{
Chapter 7 \\ From Motivation and Self- Structure to a Decision- Support Framework for Online Social Networks
}

\author{
Francisco Antunes \\ Beira Interior University, Portugal \\ Manuela Freire \\ University of Coimbra, Portugal \\ João Paulo Costa \\ University of Coimbra, Portugal
}

\begin{abstract}
Data collected from online social networks offers new possibilities for supporting organizations' daily activities. It is also common knowledge that the opinion exchange in online social networks provides a decisive contribution in decision making. It is, thus, necessary to review and bare present the motivations by which people engage in online social network and the ways in which firms can make use of such motivations in order to take advantage of online social networks as information sources for decisionmaking support. To do so, the authors of this chapter developed the decision-support social networks to extract such information, which encompasses the intertwined use of human interaction and network structure by combining human capabilities, social network analysis (SNA), and automatic data mining. In this chapter, a brief summary of the performed case studies over the proposed information model is also presented.
\end{abstract}

\section{INTRODUCTION}

The participation in online social networks have become extremely popular, corresponding to more than two-thirds of the global online population. In fact, social networking and blogging account for nearly thirty percent of all time spent on the Internet (Mander \& McGrath, 2017), suggesting that online social DOI: $10.4018 / 978-1-5225-5297-0 . c h 007$ 
networks have become a fundamental part of the global online experience (Benevenuto, Rodrigues, Meeyoung, \& Almeida, 2009) and has introduced a new organizational framework for online communities and, with it, a vibrant new research context (Boyd \& Ellison, 2008).

The use of social web data offers new possibilities for supporting organizations' daily-based activities. According to Pang and Lee (2008), "what others think" has always been an important piece of information in decision-making for almost everyone. It is also common knowledge that family and friends assume, and not in rare occasions, a decisive role in individual decision-making (choosing the color for a new car, the next holiday destination, a gift for the spouse/husband, etc.). The weight of such opinions may well match or overcome other criteria thought to be more rational or rigorous. This situation is not awkward or inexistent in firm management, as polls and market studies on costumer habits or opinionbased preferences are often incorporated into corporate decisions. The social web has made possible, as never before, to directly collect the opinions and experiences (personal and professional) of a wide range of people without any "formal inquiries", thus allowing to change the way we look at the whole decision process. Tollinen, Jarvinen, and Karjaluoto (2012), argue that social web monitoring, rather than using explicit surveys, provides more objective results on people's intentions. However, according to Murugesan (2010), several issues are still open and unsolved, like the management of the social web content (that grows day by day), its heterogeneity and the effectiveness of its extraction, just to mention a few. In addition, as reported by Batagelj, Doreian, Ferligoj, and Kejzar (2014), the majority of specific social networks (such as enterprise-based) are context limited and ignoring such contexts can impose large constraints on understanding the underlying phenomena or situation.

It is, thus, necessary to review and bare present the motivations by which people engage in online social network and the ways in which firms can make use of such motivations, in order to take advantage of online social networks as information sources for decision-making support. To do so, we developed an information model - the decision support social networks - to extract decision-making information from the interaction of people involved in online social networks (Antunes \& Costa, 2011, 2012b), which allows different working modes, ranging from very small to very large groups, without any constraint neither on how the group will organize itself nor on how it will be constituted. The idea behind such information model is that it remains an ad hoc self-organized structure, formed by people who do not have to belong to a specific firm, motivated to contribute to problem-solving (whether by firm mechanisms or by an independent self-motivation).

In this paper we take a step forward in a research field that is recognized to be in its early stages (Davenport, 2014), by providing actual implementations of the proposed information model, to extract, process, structure and analyze the collected data from context-specific online social networks. Such framework incorporates the intertwined use of human interaction and network structure, by combining human capabilities, Social Network Analysis (SNA) and automatic data mining. In the next section, a definition of online social networks is elaborated, as well as a deeper understanding of social networking phenomena, a classification and building blocks. The section ends up with the concept of group or community. Motivation to participate, language and the importance of context is also reviewed when using online social networks for decision-making purposes. After that, the decision support in social networks is deepened and the developed framework and the way to implement it is presented. Three examples of usage of the framework are then mentioned. The conclusions of these examples are also presented. Naturally, the paper ends with reference to future research and final remarks. 


\section{ONLINE SOCIAL NETWORKS}

There is not a unique definition for online social networks. While the term "social software" became a name to denote contemporary technology that supports social interaction (Boyd, 2006), there are many concurrent names for what it stands, namely groupware, computer-mediated communication software, social computing, just to mention a few.

Social software can be loosely defined as software which supports, extends, or derives added value from, human social behavior - message-boards, musical taste sharing, photo-sharing, instant messaging, mailing lists, social networking (Coates, 2005). Due to the panoply of terms, is fair to say that online social networks are web-based services, whose nature and nomenclature may vary from site to site. They allow individuals to construct a public or semi-public profile within a bounded system, articulate a list of other users with whom they share a connection, view and traverse their list of connections and those made by others within the system (Boyd \& Ellison, 2008) and interact with people in their networks (Subrahmanyama, Reich, Waechter, \& Espinoza, 2008).

While boundaries are blurred, most online social networks share a core feature: individuals offer a representation of themselves (a "profile") to others to peruse, with the intention of contacting or being contacted by others, to share opinions and facts, to meet new friends or dates, find new jobs, receive or provide recommendations, and much more (Gross \& Acquisti, 2005). They are also being used to support the creation of brand communities or for marketing research (Maclaran \& Catterall, 2002).

According to Kaplan \& Haenlein (2010), online social networks can be classified by the cross-over of social presence/media richness and self-presentation/self-disclosure (see Table 1).

Kietzmann, Hermkens, McCarthy, \& Silvestre (2011) stand that online social networks are built on seven functional blocks (see Figure 1), namely: identity, conversations, sharing, presence, relationships, reputation and groups. The authors, however, do not stand that the building blocks are mutually exclusive, nor do they all have to be present in a social media activity.

- The Identity: Represents the extent to which users reveal their identities in a social media setting (name, age, gender, profession, location, and information that portray users in certain ways), bearing privacy concerns as well;

- Conversations: Represent the extent to which users communicate with other users in a social media setting. These postings can be rich and useful, but not necessarily connected to a greater social media exchange on the same subject. Firms often need tools and capabilities that allow them to combine the information in order to produce an overall image or message;

- Sharing: Represents the extent to which users exchange, distribute, and receive content as well as the implied reasons why they meet online and associate with each other and the mapping of users' connectivity, across their entire social network;

Table 1. Social presence/media richness and self-presentation/self-disclosure

\begin{tabular}{|l|l|l|l|l|}
\hline \multicolumn{2}{|c|}{} & \multicolumn{2}{c|}{ Social Presence/Media Richness } \\
\cline { 3 - 5 } & \multicolumn{1}{c|}{ Low } & \multicolumn{1}{c|}{ Medium } & \multicolumn{1}{c|}{ High } \\
\hline $\begin{array}{l}\text { Self-presentation / Self- } \\
\text { disclosure }\end{array}$ & High & Blogs & Social networking sites & Virtual social worlds \\
\cline { 2 - 5 } & Low & Collaborative projects & Content communities & Virtual game worlds \\
\hline
\end{tabular}

Source: Adapted from Kaplan \& Haenlein (2010). 
Figure 1. The honeycomb of social media

Source: Kietzmann et al. (2011).

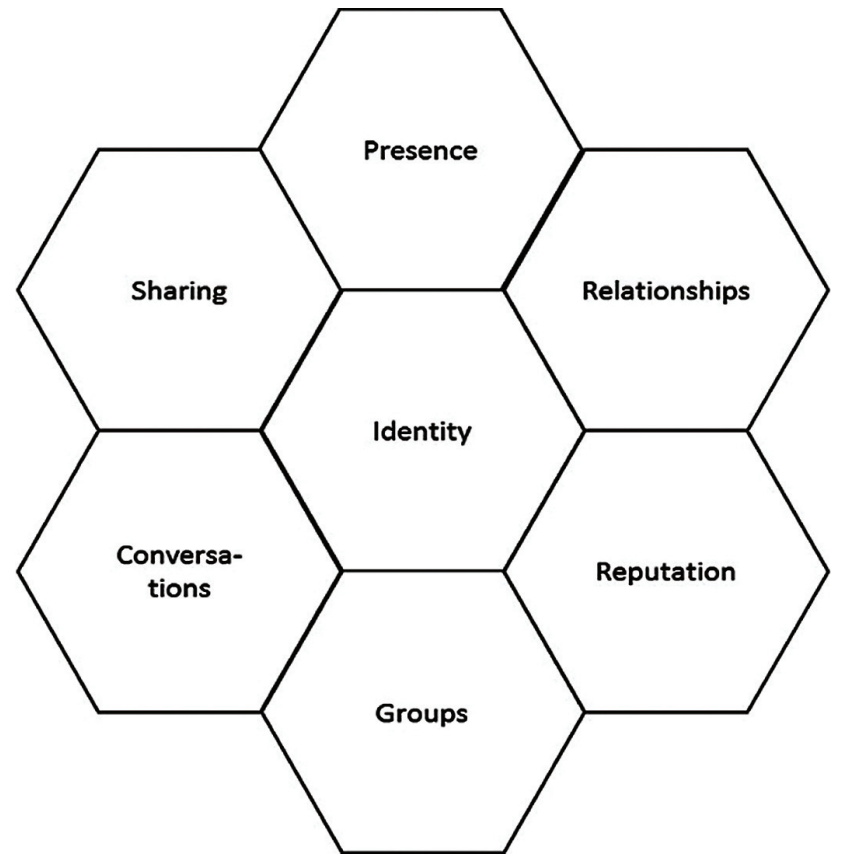

- Presence: Represents the extent to which users can know if other users are accessible. The implication of presence is that firms need to pay attention to the relative importance of user availability and user location. A firm might also want to investigate if users have a desire for selective presences, where one can be visible to some people while staying hidden to others. Another direct implication of presence is that it is linked to the traits of other functional blocks, including conversations and relationships;

- Relationships: Represent the extent to which users can be related to other users, by some form of association that leads them to converse, share objects of sociality, meet up, or simply just list each other as a friend or fan. Research shows that the denser and larger a user's portfolio of relationships is, and the more central his or her position in the portfolio, the more likely that user is to be an influential member in their network. Firms seeking to engage with their users must understand how they can maintain or build relationships, or both;

- Reputation: Is the extent to which users can identify the standing of others, including themselves, in a social media setting. In most cases, reputation is a matter of trust and has significant implications for how firms should effectively engage social media. If firms and users value their reputations and those of other users, then a metric must be chosen to provide this information. For a firm, this means that the engagement needs of its community should inform the choice of the reputation system. Once a firm has identified appropriate metrics for the reputation of its community's social media engagement, the appropriate evaluation tool must be chosen. This could be based on either objective data (e.g., the number of views or followers) or collective intelligence of the crowd (e.g., a rating system); 
- Groups: Represent the extent to which users can form communities and sub communities. Two major types of groups exist. Firstly, individuals can sort through their contacts and place their "buddies", friends, followers, or fans into different self-created groups. Secondly, groups online can be analogous to clubs in the offline world: open to anyone, closed (approval required), or secret (by invitation only). A firm would benefit from studying the groups within the community and their engagement with the other building blocks.

\section{Motivation to Participate and Timely Decisions}

Knowing that people add value, online social networks depend of their users to create a dynamic database that change and adapts continuously in time, as a result of the interactions among users and between the users and the system. Therefore, a fundamental issue is to create a critical mass of users that regularly and create, update and share knowledge (Gehrke \& Wolf, 2010; Jones, Failla, \& Miller, 2007).In order to be useful to organizations, thus taking advantage of the "wisdom of the crowds", online social networks needs to encompass enough people (please see Burke, Marlow, and Lento (2009) for a discussion on this issue, concerning generic social networks). Nonetheless, when using or analyzing an online social network for decision-making purposes, within specific contexts, the concept of "enough" people becomes blurred.

Most organizations do not possess all required knowledge within their formal boundaries and might benefit from external network connections by gaining access to new information, expertise, and ideas not available locally, while interacting informally, free from the constraints of hierarchy and local rules. Even though the employing organizations can be a direct competitors, informal and reciprocal knowledge exchanges between individuals are valued and sustained over time, because knowledge sharing is an important aspect of being a member of a technological community (Bouty, 2000; Teigland \& Wasko, 2003). The problem here is that the availability of electronic communication technologies is no guarantee that knowledge sharing will actually take place (Alavi \& Leidner, 2001; Orlikowski \& Iacono, 2001) and, therefore, the decision support social network could be dependent of the mere willingness or "kindness" of users to participate.

Creating and maintaining a core of centralized individuals is of adamant importance to overcome the problem. These individuals, should possess experience in the practice by using extrinsic motivators such as enhanced reputation to actively promote contributions and sustaining the network (Wasko \& Faraj, 2005). This core of individuals primarily built upon internal human resources, can be engaged in different types of incentives to participation, besides social rewards (personal satisfaction, reputation, feeling of belonging, tenure within the network, etc.), namely through economic incentives or career enhancements (Munson, 2008). To help generating a critical mass, managers should target individuals with longer tenure and more experience in the practice.

Another method to promote individual participation in the critical mass is the development of techniques that help to build an individual's reputation in the profession. For example, it could be helpful to assign status to individuals and make it visible. Individual reputations could become more salient when managers build bridges between physical and virtual networks, finding ways to spread the onlinedeveloped reputations, to the profession as a whole and motivating individuals, by gaining status and recognition in this way, to participate more in electronic networks of practice (Hippel \& Krogh, 2003; Wasko \& Faraj, 2005). 
As in any problem-solving process, within a decision support social network, management should set a foreseeable time for solving a problem, i.e., disseminating the problem in hand throughout the network, gathering enough people around it and performing the decision process until a solution is attained. Within a decision support social network, management opportunities for decision are, therefore, closely tied to the speed of the process, meaning that problems (or types of problems), people and decision processes need an adequate time framework to unveil.

To address this problem, it is necessary: an information cascade, where messages spread throughout the network; that the information spreads quickly, aided by the affordances of social network platforms; and that the process enables a broad reach by bridging multiple networks. The sum of these characteristics provides us nonetheless than the definition of viral information. A viral information event creates a temporally bound, self-organized, interest network in which membership is based on an interest in the information content or in belonging to the interest network of others (Hemsley \& Mason, 2013). In the case of decision support social networks, management should focus on spreading the information, regarding a decision problem, quickly and widely, making it a viral event. This should be done especially by targeting individuals with longer tenure and more experience in the practice to generate a critical mass of people, responsible for pushing the information, at least in the early stage of its propagation. It is known that if individuals are scattered throughout the network, then the information is unlikely to diffuse. If, on the other hand, they are close together, as in more context-based online social networks, then information has an increased chance for propagation (Leskovec, Adamic, \& Huberman, 2007). Therefore, the critical mass, once again, plays an important role in gathering and bringing closer external individuals.

According to Hemsley \& Mason (2013), to go viral, events are subject to two decisions by individuals in a social media network. The first is whether to watch/read the message and the second is whether to forward a viewed message. Each person who participates in a viral event has effectively voted on the content twice through his or her duel decisions, so that the resulting event has been deemed relevant and worth spreading in some way. Repeated viral events filtered in this way may result in the formation of interest networks that will grow or decay based on the accumulated social capital within the interest network. Over time, the interest networks initiated (or reinforced) by the viral event may evolve into more stable communities of practice and such evolution over time can be analyzed by Social Network Analysis as it can provide a visual (qualitative), as well as a mathematical (quantitative) analysis of human the established relations.

\section{Communication, Language, and Context}

As idea is to promote participation and information propagation within online social networks, confidentiality and language selection should not be trivial issues. On one hand, when a decision support social network only relies on internal human resources, the confidentiality expectation around problem solving is naturally bounded by corporate confidentiality agreements (implicit or explicit). On the other hand, if external human resources are implied in the process of problem solving or idea discussion, the ability for controlling the level of confidentiality is likely to be diluted. As internal and external human resources do not share the same set of motivation factors, it is not likely that they abide to confidentiality concerns in same way. Therefore, firms should be aware that open forums, are able to gather a larger amount of knowledge on a specific problem, but this is done at the expense of confidentiality loss. As 
a result, management should weight, beforehand, the importance of expanding the network outside the boundaries of the firm with the loss of control over confidentiality, thus expanding or restricting the network (using adequate profiles, for instance) accordingly to its needs.

When discussing a problem within a large or expanding online network of people, there is the need to ensure that a common language is used or, otherwise, linguistic barriers may occur. Participation will be likely hindered if people are not comfortable in expressing themselves using a certain language. In the extreme case, participation will not even take place if people do not know the used language. The use of a specific language can also inhibit or promote participation and, consequently, the network expansion might be tied to this matter. To broaden the network, the use of English language (even if it is bad English...) seems proper for fully developing the network, as English remains a dominant force within certain Internet realms. A study conducted by the Organization for Economic Co-operation and Development found that while some seventy eight percent of Web sites in OECD countries were in English, ninety one percent of Web sites on "secure-servers" were in English, and a fully ninety six percent of Web sites on secure servers in the ".com" domain were in English (Warschauer, Said, \& Zohry, 2002).

The solution for this problem is twofold. Firstly, it relies outside management boundaries, namely on the use of automated translation mechanisms (some browsers already integrate such features) or imposing the use of a common language, such as English (especially when not in control of the involved people). Secondly, because decision support situations are context-dependent, it is necessary to adjust data processing features accordingly (preferably combining human-based and automatic features), and to take into account the language where the web discourse is being produced. Only then, data become relevant and expressive in terms of substance and social context.

Particularly within online social networks, people tend to mix linguistic and non-linguistic resources in order to expedite communication. Literature review shows a perceived difficulty in structuring social networks data (Shum, Cannavacciuolo, De Liddo, Iandoli, \& Quinto, 2011), as people, in order to accelerate communication, tend to reduce the number of characters that are typed to express an idea (Freire, Antunes, \& Costa, 2015a), which poses greater strain in semantic extraction (in fact, some intervention do not even contain text, but only links and/or tags).

Altogether, this means that this data is possibly tangled, incomplete and sometimes error-prone (Antunes, Freire, \& Costa, 2016). In this case, semantics lie hidden in speech content created by the interveners and in order to reveal them, literature has focused on the study of computer mediated communications (S. Herring, 2010, 2013), natural language processing, web content analysis (S. C. Herring, 2010; Kok \& Rogers, 2016) or discourse analysis (Moser, Groenewegen, \& Huysman, 2013), just to mention a few. Most of existing studies turn out to focus on describing network properties, rather than focusing on a deep semantic analysis of the posts and later use of the findings. Although there are studies of greater complexity, that deepen the semantic analysis of web discourse contents, they do not integrate it with the analysis of network properties nor with users' interaction. The studies that incorporate SNA, as well as the semantic analysis of the posts are scarce and they remain mainly theoretical (S. C. Herring, 2013; Power \& Phillips-Wren, 2012).

Even harder to grasp, are the artifices of language such as rhetoric and wordplay (that turn out to be discursive strategies), origin, destination, intentions and reception of speech, which help to define how these interactions and respective arguments do come out. 


\section{DECISION SUPPORT IN ONLINE SOCIAL NETWORKS}

It is known that one of the most common means to collect data (regarding, for instance, marketing purposes like testing new products acceptance, determining the level of client satisfaction, accessing after-sales quality, etc.) is the use of direct surveys (whether personal or online). Nonetheless, it is also largely recognized that this type of approach possesses intrinsic problems, as people do not always reveal their true opinions or intentions, especially in face-to-face situations, which may lead to significant errors in predicting activities such as future sales or poll. The idea of collecting people's true opinions seems far more feasible within the context of social webs, than in face-to-face environments, as people can use made-up profiles to express their true ideas, instead of using their "official" profiles (please see Tollinen et al. (2012)). In term of the earlier stages of decision-making process, especially at the intelligence and design stages (as defined by Simon (1977)), this means getting better information quality, thus enhancing the possibility of better or more reality-tuned decisions, even though direct surveys have its own advantages, such as simplicity, cost and simpler data processing, that social web content analysis does not. However, the task of collecting and analyzing the content of online social networks (or web discourse) remains quite challenging as is encompasses social and technical problems that need an integrated approach.

Antunes and Costa (2012a) enlightened the interconnections of online social networking and decision support systems (DSS) concepts. They underwent a large study, using four major bibliographic resources (ISI WOK, SCOPUS, SCIRIUS and EBSCO) and, at the end of the research process, 89 papers were selected as actual interconnections of both fields. In order to reveal the concepts encompassed in the literature, network text analysis was used, as it assumes that language and knowledge can be modeled as networks of words and relations, encoding links among words to construct a network of linkages, analyzing the existence, frequencies, and covariance of terms or concepts. Social network analysis was then used to analyze and represent the obtained network of concepts (Carley, 1997). The process returned four concept clusters, which represent that the central pillars that need to be addressed when implementing a decision support social network, regardless of it size (general or context-based):

- Technical Infrastructure: Encompassing research that elaborates, develops, proposes and analyzes social networking infrastructures, for distinct purposes like data-gathering purposes, information extraction, taxonomy building, web computing, consumer support, decision automation, etc.

- Online Communities: Focusing on people, users, teams, and providing a view on the effects of online social networking among established online communities; research is directed towards group dynamics (formation, cohesion, behavior, etc.) and its effects (actual or perceived) among specific online communities.

- Network Analysis: Encompassing the analysis of organizations, companies and distributed structures, providing interpretation and decision support by means of social network analysis measures (centrality, betweenness, closeness, degree, etc.).

- Knowledge Management: Addressing the so-called "wisdom of the crowds", using the lens of knowledge management, namely its use (actual and perceived), usefulness and setbacks towards the objectives of knowledge creation, sharing, encoding, retrieval and representation. 


\section{Integrating Discursive and Technical Issues}

Understanding why people participate in online social networks seems, therefore, crucial for developing and engaging users within a decision support social network (Antunes \& Costa, 2014) and to integrate the all above mentioned issues we developed a framework to extract, process, structure and analyze the collected data from context-specific social networks. Such framework incorporates human interaction and network structure, by combining human capabilities, Social Network Analysis (SNA) and automatic data mining. According to Marmo (2011), the combination of SNA and web mining gives an innovative degree of detail in the analysis of social networks that can be useful for decision-making, by providing a better structuring and understanding of the logical sequence of the produced contents of an online social network (Antunes \& Costa, 2011).

Although online social networks seem to be well fitted for searching information (Suki, Ramayah, Ming, \& Suki, 2011) and for developing divergence processes (typical activities within the intelligent phase of the decision process), how to use online social networks for structuring and/or convergence procedures or activities remains elusive. Nonetheless, produced contents, need to be tagged by users or automatically supplied by the system, creating a folksonomy that can be used afterwards for convergence purposes. Classifications according to argumentation models can be available, or created by the users, for which semantic techniques (Web 3.0/semantic) seem to be quite promising (Schneider, Groza, \& Passant, 2013; Turoff, Hiltz, Bieber, Fjermstad, \& Rana, 1999). The combination of information filtering, classification, sorting and displaying techniques, becomes essential to support the different cognitive styles of decision-makers engaged in contingent decision processes (Colombo, Antonietti, Sala, \& Caravita, 2013).

However, as in the previous section, there are several limitations, which cannot be disregarded, making the treatment, organization and retrieval and analyzing the content of social web content (or web discourse), commonly known as posts, quite challenging:

- $\quad$ Processing the Text of Posts: Processing the textual data contained in the posts requires tools to clean and standardize them (as the ideas contained in posts can be diffused along sentences full of characters and punctuation, to emphasize situations), in order to capture the semantic aspects that allow to go beyond the mere identification of keywords, ranking of concepts, etc. (Robinson, Webber, \& Eifrem, 2013). The writing style commonly used in these platforms has a pattern out of the ordinary that sometimes makes it incomprehensible to those who are not part of the conversation and/or that culture or context, thus making it very hard to make it "machine- understandable" (Antunes et al., 2016). This is because social actors often make mistakes, spelling and/or grammar, use abbreviations (ASAP $=$ as soon as possible), symbols $(:(=$ sad $)$ "stretch" the words ("nooooo"), include links, images, audio and video (Bodomo, 2010).

- Semantics: Usually, posts do not share common ontologies, as they are created and changed constantly. The non-existence of standards to express web data semantics hinders the possibilities for integrating applications to analyze them. In addition, the interaction within social networks, and its consequent discursive exchanges, often produces information in an informal and unstructured language, that social tagging, used in folksonomies, fails to address; 
- Post Dimension (Number of Characters): In order to accelerate communication people tend to reduce the number of characters that are typed to express an idea (Antunes \& Costa, 2015), which poses greater strain in semantic extraction;

- Data Characteristics: Social networks are much more than a simple set of links and texts. They are interactive and dynamic complex networks with several links that correspond not only to users and "friends" (followers), but also a set of links between posts, videos, photos, etc. (S. C. Herring, 2010; Robinson et al., 2013). In addition, a user can comment posts in a successively way (post $\rightarrow$ comment; comment $\rightarrow$ comment) and share them. This raises the issues of visualization and graphical analysis. The collected data falls into three categories: structured (users), semi-structured (posts) and unstructured (concepts found within posts);

Processing the data contained in the textual interchanges, within an online social network, usually known as posts, requires tools to clean and standardize them (as the ideas contained in posts can be diffused along sentences full of characters and punctuation, to emphasize situations). This is done to capture the semantic aspects that allow to go beyond the mere identification of keywords, ranking of concepts, etc. (Robinson et al., 2013). To do so, the developed framework, depicted in Figure 2, starts by extracting data from a context-specific online social network. Throughout the process, an iterative three-stage process will generate several networks, which are recurrent and iterative.

Figure 2. Workflow of the developed approach Source: (Freire, Antunes, \& Costa, 2017).

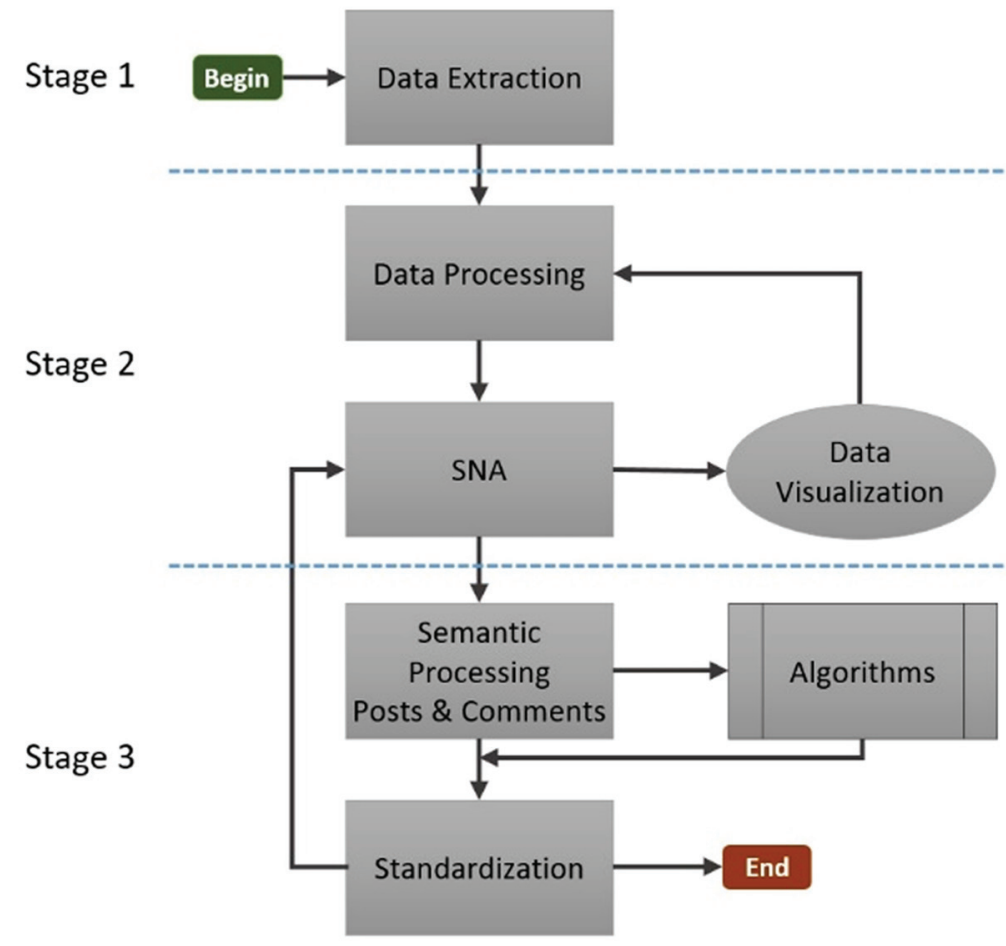




\section{Data Extraction}

The first step is to gather data with all interacting social actors (user $\rightarrow$ user) and respective posts (user $\rightarrow$ post) and data regarding the posts and comments.

Such data makes it possible to study the social interaction (user $\rightarrow$ user), as well as to study the semantics of the content of a post. To that purpose, a two-mode network is used, as it allows to represent three sets of nodes in the same graph (Ikematsu \& Murata, 2013), allowing to analyze the three levels of interactions between social actors, i.e. the interaction between: users; user and posts; posts and concepts. The main issue here is to be able to affect a post to a user and, in turn, a concept to a post, in order to know who said what, as shown in Figure 3.

\section{Data Processing and Interpretation}

In order to simultaneously analyze the three levels of the network (the interaction between: users; user and posts; posts and concepts) a transformation of the two-mode network into a one-mode network (Borgatti, 2009) is required. This method binds the two datasets using common nodes. By doing so, data can be represented by a square matrix, where rows and columns represent the nodes of the two unified datasets. In this matrix, a " 1 " in a given position means that there is a connection between the line node and the column node of that position.

Figure 3. Levels of analysis Source: (Freire et al., 2017).

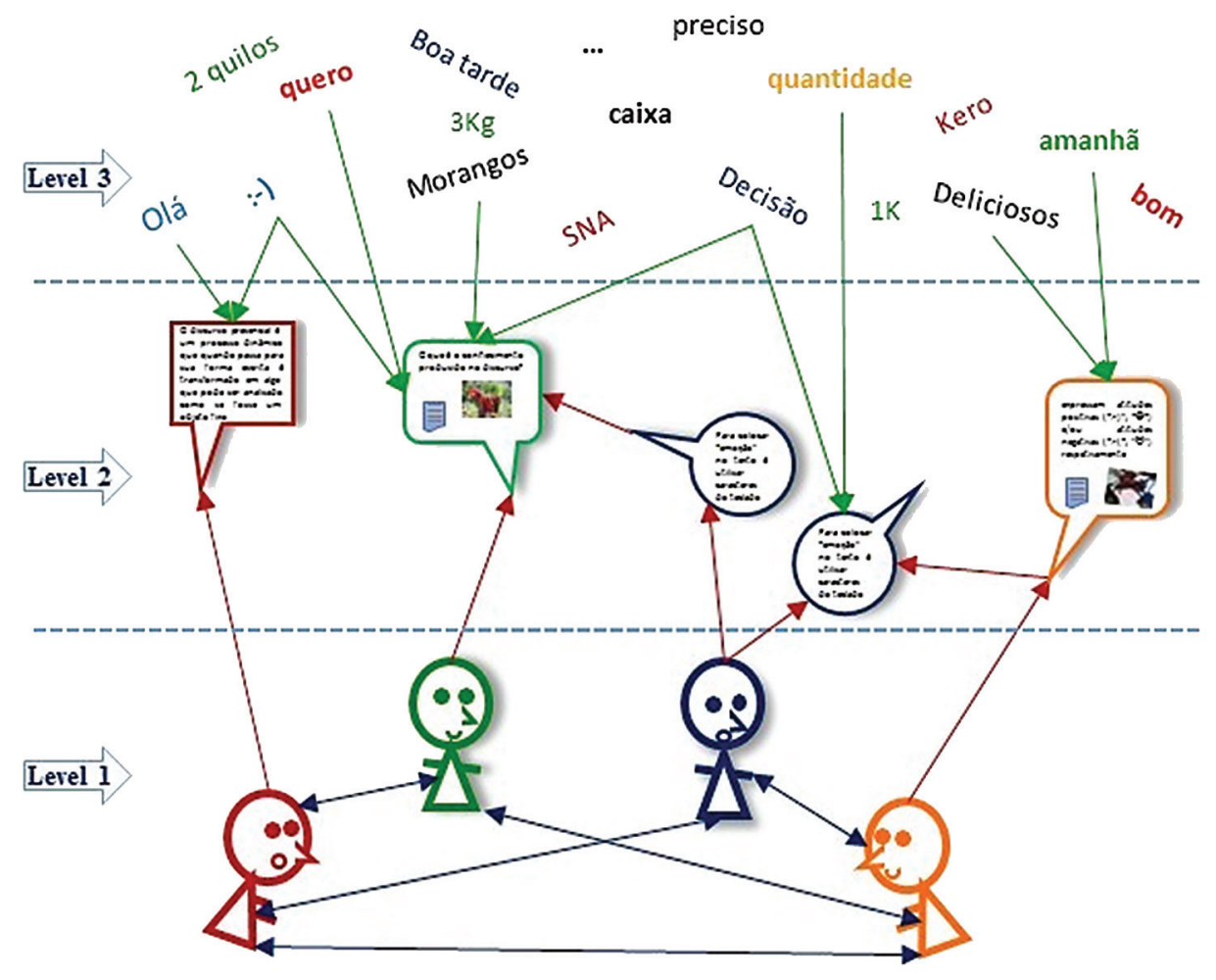


It is then necessary to interpret the data using SNA, namely by using in-degree and out-degree metrics, to eliminate irrelevant data of unconnected nodes, i.e., nodes with in-degree and out-degree equaling zero. These posts usually are derived from automatic messages. After this cleaning, it is necessary to perform the junction of the data with all interacting social actors (user $\rightarrow$ user) and respective posts (user $\rightarrow$ post interactions) and data regarding the posts and comments, in order to create a single network.

\section{Semantics Processing}

The first step in this stage is to transform posts and comments, into networks of words, as a basis to perform the semantic analysis of posts using text mining and SNA. The process of data analysis is an iterative recurrent process, where human involvement is essential for a systematic analysis of the obtained results and to verify if any adjustments are deemed necessary. The visualization of the data by means of SNA tools and metrics helps to accelerate this process.

A simple way to transform text into SNA interpretable data is to "split" every discursive exchange (posts and comments) into individual words. The result of this action is a network where each concept is a node, regardless of its existence in another post or comment. In doing so, the content of each post is summarized through a semantic sub-network, which is constructed by establishing a relationship between the pairs of words contained in each post.

In order to identify standardized network concepts, our proposal establishes the creation of a Cleaning Database (Provost \& Fawcett, 2013) to process the unstructured data from the posts. After identifying irrelevant data, the Cleaning Database is then configured to discard them in a second processing.

The next step is to detect keywords, since the extraction of keywords is an important technique for identifying the most used and relevant concepts in posts (Aggarwal, 2011). For that purpose, a new network, consisting of the users, received posts and concepts contained in them, is then created. In this network, each concept constitutes an entity with its own ID. Concepts with the same semantic meaning are then sought (knowing that each concept has a different ID), and the same ID is assigned to all concepts bearing the same meaning, by replicating the links from the keyword to the post. We find that the graphical visualization of the network can be very helpful in this step. A network of keywords is then created, constituted by users, posts and concepts contained therein. This network is built with concept's unicity (keywords), allowing to count (using the out-degree metric) the number of times each relevant concept was posted or linked.

As described, the devised iterative process needs a combination of human and computerized procedure that allow to build semantic networks that summarize the discursive exchanges between users, where text mining allows to convert users' posts into multiple pieces (as many, as the concepts that exist in a post). In addition, the use of SNA software over the obtained networks, which incorporates a variety of visualization techniques and algorithms, translates concepts, extracted from posts and comments, into something more compact and, therefore, more understandable. Through SNA metrics (please see Arif (2015) for a detailed review), it is not only possible to identify the structure of the users' network, but also to "translate" the network into a graphical representation. Such representation makes it possible to identify users acting as leaders (who will make most of the orders) and/or who influence others (product recommendation), as well as to determine the relative strength of the leader through a key concept. Such information can help to devise more adjusted (we could almost say "chirurgical") marketing strategies that target the users that will better propagate its effects on a lesser cost. 


\section{APPLICATION CASE STUDIES}

To test and illustrate how the described framework can be used to decision support, we present in this section a brief summary of three distinct situations, which allowed the refinement over its sequential application, over different case settings and participation motivations (the references for the detailed case studies are provided ahead).

Although the framework does not specify any online social network for its application, we used Facebook in all presented cases, in order to use the app Netvizz (https://apps.facebook.com/netvizz/), a free tool that provides a simple and quick way to import data by using the module "group data", to collect the data. The module allowed extracting tabular files of users' activities around the posts of the created Facebook groups.

To perform data extraction we used NodeXL (https://nodexl.codeplex.com/) and Gephi (https://Gephi. org/), an open-source software that allows a simple visualization and manipulation of networks, as well as the calculation of the most important metrics of SNA, was used for data processing along the stages of the framework.

Regarding semantic analysis, in order to interconnect concepts to posts and comments, two approaches were followed. The first one obtained a summary of each discursive exchange, while the second identified the network of keywords. We explored the data with text mining, building semantic networks that summarized the discursive exchanges between users. Text mining allowed to convert posts into multiple pieces (as many, as the concepts that exist in a post). In addition, the SNA software that incorporated a variety of visualization techniques and algorithms, helped to translate the concepts, extracted from posts and comments, into something more compact and, therefore, more understandable. The calculation of different SNA metrics and the analysis of multiple networks allowed a richer, more structured view of those involved in discourse, as well as the most used concepts.

The identification and standardization of network concepts was performed using Microsoft Excel VBA (Visual Basic for Applications) algorithms. Data were then processed, using MS-Excel, producing Cleaning Databases that were created and imported into Gephi, making it possible to generate and graphically visualize the produced networks.

\section{The Collaborators' Annual Lunch}

We created a closed group for a small group of collaborators of a large company, geographically spread all over the country, to debate the location of their traditional annual lunch (Freire et al., 2015a). They voluntarily participated with different levels of engagement. Some gathered information (mainly webbased) on the topic and reasoned about it. The organization of a simple lunch had an associated logistics process, because when gathering a group, the number of people conditions the choice of the location. Consequently, the organizer needed to know who would attend, as well as their menu and location preferences, in order to satisfy the attendees. Accordingly, the decision-making required a thorough search of the suggested alternatives, reliable information on the consequences and preferences, to get the intended results.

This was the first attempt to use the framework as a decision-support tool, encompassing a situation where all involved users were internal to the company, self-motivated and bearing a strong group feeling. 
The data were collected between 22-Nov-2014 and 11-Jan-2015 and, afterwards, we applied SNA techniques in order to study the network, which was analyzed from the ego-centric perspective (Ma, Gustafson, Moitra, \& Bracewell, 2010). The group were aware of the language in use, as well as the associated semantics and therefore, there was no need for ontologies to decipher what is implied within the speech. The use of this relatively small network allowed limiting the number of elements under review. In this way, it was possible to study, more thoroughly, the network in terms of its composition, characteristics (through metrics on the type of interaction established between the different social actors) and structure.

The group interaction had low activity, with short and simple posts, providing a low number of keywords found in the analyzed speech. This situation was expected as it is known that the language used in web discourse is usually characterized by a tendency to reduce the amount character to express an idea and, consequently, to speed up the communication process. It was possible to state that, within the analyzed posts, only one had a larger number of concepts.

The analysis of the multiple networks, as well as the calculations of different SNA metrics, allowed a rich and structured view of the discourse, as well as most used concepts. This allowed to effectively produce a decision reconstruction (especially when gathering information on the problem and when seeking alternatives for its resolution - that could be translated into the design and intelligence phases of the decision process), thus producing a clear understanding on how many people would attend the lunch, the intended place and menu.

\section{A General Strike of an Airline Company}

The objectives of this study (Freire, Antunes, \& Costa, 2015b) were to analyze costumer-generated data, during a period of a ten days strike (in May of 2015), encompassing a situation where the involved users were external to the company, self-motivated and without a group feeling. The main goal was to understand if it was possible to structure the produced posts within the airline's Facebook social network, in order to check service and responsiveness of the airline company to customers, as well as to develop indicators to review and/or fortify strategies in customer service on a strike situation, using SNA methodology.

The data, collected not only during the ten days strike, but also during the following five days, allowed constructing several networks and subnetworks. By analyzing the content of the posts we perceived that they could be categorized, which meant that posts provided the means to better focus/create task groups to address cases of complaints, requests for help/support in changing a reservation, requests for information (about hotel, luggage collection, refund procedures, etc.).

In the analyzed posts, many customers complained that the call center did not answer calls, they had no response to e-mails, airports with service counters (personal assistance) were closed and the airline company website did not have any information on the strike. Visualization allowed to identify relevant conversations and to provide direct and immediate insights about the customers' feelings, allowing faster reactions to whether or not client dissatisfaction sentiment is being developed or aggravated.

Posts' analysis and network visualization could have helped the airline company to identify the problems in traditional channels (call centers, e-mail, etc.) and to address them more quickly in order to prevent future service breakdowns due to strike situations. In addition, visualization and identification of keywords could have been used to reinforce the need for delivering permanent information (for instance through online channels or service counters) on: whether a flight needed to be canceled or not; the list of canceled or available flights; how to reschedule/change the date of a flight. 


\section{The Strawberries Sale}

The "strawberries sale" was implemented within a group of potential customers (Freire et al., 2017). A small promotional box of strawberries was delivered at the potential customers' workplaces, with the following attached message: "Directly from the producer to the customer. To place order intentions, please join the Strawberries group created on Facebook and leave yours". Then, a strawberry grower was contacted to deliver those orders at customers' workplaces.

The decision support problem was to estimate the required strawberries quantity to meet the customers' requests (as no pre-established order form was available), solely based on their posts on Facebook. We intended to verify if the semantic analysis of the posts could be used to effectively recommend the necessary quantities to transport and deliver, solely based on expressed intentions (there were no actual purchase orders involved). We concluded that it was possible to extract insights for decision support, namely to predict the behavior of customers, thus allowing to create new visions based on real data, resulting from the interaction and discursive exchanges between users. By using SNA metrics it was not only possible to identify the structure of the users' network, but also to "translate" the network into a graphical representation. Such representation made possible to identify users acting as leaders (who would make most of the orders) and/or who influenced others (product recommendation), as well as to determine the relative strength of the leader through a key concept. Such information could help to devise more adjusted (we could almost say "chirurgical") marketing strategies to target the users that could better propagate its effects on a lesser cost.

We concluded that not only it was possible to recommend the needed quantities to be transported and delivered to customers, but also we have identified the customers who ordered the most and the leaders of the customers' group.

\section{FUTURE RESEARCH DIRECTIONS}

The analysis and visualization of concepts extracted from the web discourse can be used as insights for follow-up decisions, as they allow efficient access to key information. The obtained results provided information on the key terms that were used during the discursive exchanges, in order to be used to analyze different alternatives to support decision-making.

We intend to determine if the combination of context-specific and context-generic semantics extraction procedures would benefit from an integrated approach, as well as the development of a deeper combination of text and data mining and graphical visualization of the text and data mining results improve the effectiveness of semantic extraction frameworks, especially for prediction purposes. To do so, we plan to broaden the scope of our studies, in order to determine to what extent it can be used for prediction. Some of the planned case studies regard: the number of club fans that will go to a stadium; the number of people attending a demonstration and/or event; the number of people interested in a particular promotional campaign; the number of people who oppose a measure or policy; the acceptance of a new product and/or service.

In addition, we aim to explore and develop new feature/algorithms that could identify interest and dishonest behavior in social web networks (or at least to flag the suspicion to the users), as the actual implementation is unable to do so. 


\section{CONCLUSION}

Starting from the existing connections between online social network and decision support, the motivations for people to engage in online social networks were reviewed. There are extrinsic and intrinsic factors. People contribute to social networks when they understand that it enhances their reputation and recognition and to some extend because they feel it is enjoyable to help others. The participation or contribution of people engaged in social networking is not without problems.

Considering that a solution to a certain problem is expected within a decision support social network, some potential problems may arise: the network can be dependent of the mere willingness or "kindness" of users to participate; decisions can emerge out of time; a common language may not be easy to find; and confidentiality can be out of control. These potential problems were framed and several tactics or policies were put forward so that firms could overcome them.

The analysis and visualization of concepts used in web discourse can be used as insights for follow-up decisions, as it allows efficient access to key information. The obtained results provide information on the key terms used during the discursive exchanges and can be used to analyze various alternatives of a problem and to support decision-making. By identifying the number of times that the concepts appear in all posts, it is possible to determine any possible preferences and opinions of users. By putting all the group members and their respective interests in the same level, we get an outline of the views and group positions (in favor or against). Therefore, when a choice has to be made, argumentation gets into the "game" and network analysis can help to capture it. Therefore, network analysis is particularly suitable for the study of social network decision-making because it allows to recognize the dynamic nature of networks, providing tools and techniques for measuring and evaluating its changes.

To do so, we used the proposed framework to extract, process, structure and analyze the collected data from a social network. We explored social networks, combining two different perspectives: the social interactions between users and the semantic analysis of their discourse.

It should be noted that the construction of datasets obtained from Facebook are inexpensive and easy to extract, so it is easier and faster to obtain reports on the opinions of customers, as compared to conducting market researches or surveys. Increasingly, customers have the ability to express their needs, feelings, desires, and frustrations about a product, service and/or company in real time. Therefore, we stand that the proposed framework can be useful to extract a set of orientations for decision-making. We could conclude that it is possible to extract insights for decision support, namely to predict the behavior of customers.

\section{ACKNOWLEDGMENT}

This research was supported by the by the Portuguese Foundation for Science and Technology (FCT). [Grant number UID/MULTI/00308/2013]. 


\section{REFERENCES}

Aggarwal, C. C. (2011). Social Network Data Analytics. New York: Springer. doi:10.1007/978-1-4419$8462-3$

Alavi, M., \& Leidner, D. E. (2001). Review: Knowledge management and knowledge management systems: Conceptual foundations and research issues. Management Information Systems Quarterly, 25(1), 107-136. doi:10.2307/3250961

Antunes, F., \& Costa, J. P. (2011). Decision Support Social Network. Paper presented at the 6th Iberian Conference on Information Systems and Technologies (CISTI), Chaves, Portugal.

Antunes, F., \& Costa, J. P. (2012a). Disentangling Online Social Networking and Decision Support Systems Research Using Social Network Analysis. Paper presented at the EWG-DSS Liverpool-2012 Workshop on Decision Support Systems \& Operations Management Trends and Solutions in Industries, Liverpool, UK.

Antunes, F., \& Costa, J. P. (2012b). Integrating decision support and social networks. Advances in Human-Computer Interaction, 2012, 1-10. doi:10.1155/2012/574276

Antunes, F., \& Costa, J. P. (2014). Reviewing Motivations for Engaging in Decision Support Social Networks. International Journal of Human Capital and Information Technology Professionals, 5(1), 1-14. doi:10.4018/ijhcitp.2014010101

Antunes, F., \& Costa, J. P. (2015). The Impact of Online Social Networks on Decision Support Systems. In L. Mola, F. Pennarola, \& S. Za (Eds.), From Information to Smart Society (Vol. 5, pp. 75-85). Springer International Publishing. doi:10.1007/978-3-319-09450-2_7

Antunes, F., Freire, M., \& Costa, J. P. (2016). Semantic web and decision support systems. Journal of Decision Systems, 25(1), 79-93. doi:10.1080/12460125.2015.1087293

Arif, T. (2015). The Mathematics of Social Network Analysis: Metrics for Academic Social Networks. International Journal of Computer Applications Technology and Research, 4(12), 889-893. doi:10.7753/ IJCATR0412.1003

Batagelj, V., Doreian, P., Ferligoj, A., \& Kejzar, A. (2014). Understanding Large Temporal Networks and Spatial Networks: Exploration, Pattern Searching, Visualization and Network Evolution. Chichester, UK: John Wiley \& Sons Ltd. doi:10.1002/9781118915370

Benevenuto, F., Rodrigues, T., Meeyoung, C., \& Almeida, V. (2009, November 4-6,). Characterizing User Behavior in Online Social Networks. Paper presented at the Internet Measurement Conference (IMC'09), Chicago, IL. doi:10.1145/1644893.1644900

Bodomo, A. B. (2010). Computer-Mediated Communication for Linguistics and Literacy: Technology and Natural Language Education. Hershey, PA: Information Science Reference. doi:10.4018/978-160566-868-0 
Borgatti, S. P. (2009). 2-Mode Concepts in Social Network Analysis. In R. A. Meyers (Ed.), Encyclopedia of Complexity and System Science (pp. 8279-8291). Larkspur, CA: Springer. doi:10.1007/978-0-38730440-3_491

Bouty, I. (2000). Interpersonal and interaction influences on Informal resource exchanges between R\&D researchers across organizational boundaries. Academy of Management Journal, 43(1), 50-65. doi:10.2307/1556385

Boyd, D. M. (2006). The significance of social software. In T. N. Burg \& J. Schmidt (Eds.), BlogTalks Reloaded. Social Software - Research \& Cases (pp. 15-30). Norderstedt, Germany: Books on Demand $\mathrm{GmbH}$.

Boyd, D. M., \& Ellison, N. B. (2008). Social network sites: Definition, history, and scholarship. Journal of Computer-Mediated Communication, 13(1), 210-230. doi:10.1111/j.1083-6101.2007.00393.x

Burke, M., Marlow, C., \& Lento, T. (2009). Feed Me: Motivating Newcomer Contribution in Social Network Sites. Paper presented at the CHI 2009, Boston, MA. doi:10.1145/1518701.1518847

Carley, K. M. (1997). Network Text Analysis: The Network Position of Concepts. In C. W. Roberts (Ed.), Analysis for the Social Sciences: Methods for Drawing Statistical Inferences from Texts and Transcripts (pp. 79-100). Mahwah, NJ: Laurence Erlbaum Associates, Inc.

Coates, T. (2005). An addendum to a definition of Social Software. PLASTICBAG. ORG, 5. Retrieved from http://www.plasticbag.org/archives/2005/01/an_addendum_to_a_definition_of_social_software/

Colombo, B., Antonietti, A., Sala, R., \& Caravita, S. C. S. (2013). Blog Content and Structure, Cognitive Style and Metacognition. International Journal of Technology and Human Interaction, 9(3), 1-17. doi:10.4018/jthi.2013070101

Davenport, T. H. (2014). Big data at work: dispelling the myths, uncovering the opportunities. Harvard Business School Press. doi:10.15358/9783800648153

Freire, M., Antunes, F., \& Costa, J. P. (2015a). Exploring social network analysis techniques on decision support. Paper presented at the 2nd European Conference on Social Media ECSM 2015, Porto, Portugal.

Freire, M., Antunes, F., \& Costa, J. P. (2015b). Social network analysis to support decision-making. Paper presented at the Workshop on Assessment Methodologies - energy, mobility and other real world applications (WAM 2015), Coimbra, Portugal.

Freire, M., Antunes, F., \& Costa, J. P. (2017). A Semantics Extraction Framework for Decision Support in Context-Specific Social Web Networks. In L. S. Linden I., Colot C (Ed.), Decision Support Systems VII. Data, Information and Knowledge Visualization in Decision Support Systems (pp. 133-147). Springer. doi:10.1007/978-3-319-57487-5_10

Gehrke, N., \& Wolf, P. (2010). Towards Audit 2.0 - A Web 2.0 Community Platform for Auditors. Paper presented at the 43rd Hawaii International Conference on System Sciences (CD-ROM), Kauai, HI. doi:10.1109/HICSS.2010.407 
Gross, R., \& Acquisti, A. (2005). Information Revelation and Privacy in Online Social Networks. Paper presented at the 2005 ACM Workshop on Privacy in the Electronic Society (WPES'05), Alexandria, VA. doi:10.1145/1102199.1102214

Hemsley, J., \& Mason, R. M. (2013). Knowledge and Knowledge Management in the Social Media Age. Journal of Organizational Computing and Electronic Commerce, 23(1-2), 138-167. doi:10.1080/109 19392.2013.748614

Herring, S. (2010). Web Content Analysis: Expanding the Paradigm. In J. Hunsinger, L. Klastrup, \& M. Allen (Eds.), The International Handbook of Internet Research (pp. 233-249). New York: Springer.

Herring, S. (2013). Discourse in Web 2.0: Familiar, Reconfigured, and Emergent. In D. Tannen \& A.M. Trester (Eds.), Discourse 2.0: language and new media (pp. 1-25). Washington, DC: Georgetown University Press.

Herring, S. C. (2010). Web Content Analysis: Expanding the Paradigm. In J. Hunsinger, L. Klastrup, \& M. Allen (Eds.), The International Handbook of Internet Research (pp. 233-249). New York: Springer.

Herring, S. C. (2013). Discourse in Web 2.0: Familiar, Reconfigured, and Emergent. In D. Tannen \& A. M. Trester (Eds.), Discourse 2.0: language and new media (pp. 1-25). Washington, DC: Georgetown University Press.

Hippel, E., \& Krogh, G. (2003). Open Source Software and the "Private-Collective" Innovation Model: Issues for Organization Science. Organization Science, 14(2), 208-223. doi:10.1287/orsc.14.2.209.14992

Ikematsu, K., \& Murata, T. (2013). A Fast Method for Detecting Communities from Tripartite Networks. In A. Jatowt, E.-P. Lim, Y. Ding, A. Miura, T. Tezuka, G. Dias, \& B. T. Dai et al. (Eds.), Social Informatics (pp. 192-205). Springer. doi:10.1007/978-3-319-03260-3_17

Jones, B., Failla, A., \& Miller, B. (2007). Tacit Knowledge in Rapidly Evolving Organisational Environments. International Journal of Technology and Human Interaction, 3(1), 49-71. doi:10.4018/ jthi.2007010104

Kaplan, A. M., \& Haenlein, M. (2010). Users of the world, unite! The challenges and opportunities of Social Media. Business Horizons, 53(1), 59-68. doi:10.1016/j.bushor.2009.09.003

Kietzmann, J. H., Hermkens, K., McCarthy, I. P., \& Silvestre, B. S. (2011). Social media? Get serious! Understanding the functional building blocks of social media. Business Horizons, 54(3), 241-251. doi:10.1016/j.bushor.2011.01.005

Kok, S., \& Rogers, R. (2016). Rethinking migration in the digital age-transglocalization and the Somali diaspora. Global Networks, 1-24.

Leskovec, J., Adamic, L. A., \& Huberman, B. A. (2007). The Dynamics of Viral Marketing. ACM Transactions on the Web, 1(1).

Ma, H., Gustafson, S., Moitra, A., \& Bracewell, D. (2010). Ego-Centric Network Sampling in Viral Marketing Applications. In I.-H. Ting, H.-J. Wu, \& T.-H. Ho (Eds.), Mining and Analyzing Social Networks (pp. 35-50). Springer. doi:10.1007/978-3-642-13422-7_3 
Maclaran, P., \& Catterall, M. (2002). Researching the social Web: Marketing information from virtual communities. Marketing Intelligence \& Planning, 20(6), 319-326. doi:10.1108/02634500210445374

Mander, J., \& McGrath, F. (2017). Flagship Report Q1 2017 - Time Spent on Social Networks or Services. Global Web Index Media.

Marmo, R. (2011). Web Mining and Social Network Analysis. In H. Zhang, R. S. Segall, \& M. Cao (Eds.), Visual Analytics and Interactive Technologies: Data, Text and Web Mining Applications (pp. 202-211). Hershey, PA: Information Science Reference. doi:10.4018/978-1-60960-102-7.ch012

Moser, C., Groenewegen, P., \& Huysman, M. (2013). Extending Social Network Analysis with Discourse Analysis: Combining Relational with Interpretive Data. In T. Özyer, J. Rokne, G. Wagner, \& A. Reuser (Eds.), The Influence of Technology on Social Network Analysis and Mining (pp. 547-561). New York: Springer. doi:10.1007/978-3-7091-1346-2_24

Munson, S. A. (2008). Motivating and enabling organizational memory with a wrokgroup Wiki. Paper presented at the WikiSym08 2008 International Symposium on Wikis, Porto, Portugal.

Murugesan, S. (2010). Handbook of Research on Web 2.0, 3.0, and X.0-Technologies, Business, and Social Applications. Hershey, PA: IGI-Global. doi:10.4018/978-1-60566-384-5

Orlikowski, W. J., \& Iacono, C. S. (2001). Desperately Seeking the "IT" in IT Research - A Call to Theorizing the IT Artifact. Information Systems Research, 12(2), 121-134. doi:10.1287/isre.12.2.121.9700

Pang, B., \& Lee, L. (2008). Opinion Mining and Sentiment Analysis (Vol. 2). Now Publishers Inc.

Power, D. J., \& Phillips-Wren, G. (2012). Impact of Social Media and Web 2.0 on Decision-Making. Journal of Decision Systems, 20(3), 249-261. doi:10.3166/jds.20.249-261

Provost, F., \& Fawcett, T. (2013). Data Science for Business: What You Need to Know about Data Mining and Data-Analytic Thinking. O'Reilly Media.

Robinson, I., Webber, J., \& Eifrem, E. (2013). Graph Databases. Gravenstein Highway North. Sebastopol, CA: O'Reilly Media, Inc.

Schneider, J., Groza, T., \& Passant, A. (2013). A review of argumentation for the Social Semantic Web. Semantic Web, 4(2), 159-218. doi:10.3233/SW-2012-0073

Shum, S. B., Cannavacciuolo, L., De Liddo, A., Iandoli, L., \& Quinto, I. (2011). Using Social Network Analysis to Support Collective Decision-Making Process. International Journal of Decision Support System Technology, 3(2), 15-31. doi:10.4018/jdsst.2011040102

Simon, H. A. (1977). The New Science of Management Decision. Upper Saddle River, NJ: Prentice Hall.

Subrahmanyama, K., Reich, S. M., Waechter, N., \& Espinoza, G. (2008). Online and offline social networks: Use of social networking sites by emerging adults. Journal of Applied Developmental Psychology, 29(6), 420-433. doi:10.1016/j.appdev.2008.07.003

Suki, N. M., Ramayah, T., Ming, M. K. P., \& Suki, N. M. (2011). Factors Enhancing Employed Job Seekers Intentions to Use Social Networking Sites as a Job Search Tool. International Journal of Technology and Human Interaction, 7(2), 38-54. doi:10.4018/jthi.2011040105 
Teigland, R., \& Wasko, M. M. (2003). Integrating Knowledge through Information Trading: Examining the Relationship between Boundary Spanning Communication and Individual Performance. Decision Sciences, 34(2), 261-286. doi:10.1111/1540-5915.02341

Tollinen, A., Jarvinen, J., \& Karjaluoto, H. (2012). Opportunities and Challenges of Social Media Monitoring in the Business to Business Sector. Paper presented at the The 4th International Business and Social Science Research Conference, Dubai, UAE.

Turoff, M., Hiltz, S. R., Bieber, M., Fjermstad, J., \& Rana, A. (1999). Collaborative Discourse Structures in Computer Mediated Group Communications. Journal of Computer-Mediated Communication, 4(4), $1050-1079$.

Warschauer, M., Said, G. R. E., \& Zohry, A. (2002). Language Choice Online: Globalization and Identity in Egypt. Journal of Computer-Mediated Communication, 7(4).

Wasko, M. M., \& Faraj, S. (2005). Why should I share? Examining social capital and knowledge contribution In electronic networks of practice. Management Information Systems Quarterly, 29(1), 35-57.

\section{KEY TERMS AND DEFINITIONS}

Case Study: A process or record of research into the development of a particular person, group, or situation over a period of time in order to analyze a particular instance of something used or analyzed in order to illustrate a thesis or principle.

Data Extraction: The act or process of retrieving data out of (usually unstructured or poorly structured) data sources for further data processing or data storage (data migration).

Decision-Making: The thought process of selecting a logical choice from the available options by weighting the positives and negatives of each option and considering all the alternatives. For effective decision making, a person must be able to forecast the outcome of each option as well, and based on all these items, determine which option is the best for that particular situation.

Group: A set of people who act together in a certain context and work environment.

Online Social Network: A web-based service, whose nature and nomenclature may vary, that permits individuals to construct public or semi-public profiles and allows their interaction.

Semantics: Regards the branch of linguistics and logic concerned with meaning. The two main areas are logical semantics, concerned with matters such as sense and reference and presupposition and implication, and lexical semantics, concerned with the analysis of word, phrase and text meanings and relations between them.

Social Network Analysis: The mapping and measuring of relationships and flows between people, groups, organizations, computers, URLs, and other connected information/knowledge entities. The nodes in the network represent the entities, while the links show relationships or flows between the nodes. SNA provides both a visual and a mathematical analysis of the created networks. 